\title{
Trayectorias residenciales de Hogares Inmigrantes Peruanos de bajos Ingresos en Santiago de Chile
}

\author{
Residential trajectories of low-income \\ Peruvian Immigrant Households in Santiago de Chile
}

Alejandra Rasse Figueroa 1

Angélica Sanzana Medina ${ }^{2}$

\begin{abstract}
Resumen
Este estudio busca comprender la historia residencial de los hogares de inmigrantes peruanos en la Región Metropolitana, desde su llegada hasta su situación actual, a partir de sus propias palabras y experiencias. Desde una perspectiva biográfica, a través de las trayectorias residenciales de ocho hogares, se concluye que la trayectoria residencial de los hogares de inmigrantes peruanos en la ciudad de Santiago, desde su llegada hasta la actualidad, se encuentra conformada por elementos decisionales de cambio y de continuidad. Los elementos de cambio son los que tienen relación con la transformación en su acceso a bienes y/o servicios, y, en definitiva, su inserción en la nueva ciudad. Mientras que los elementos de continuidad corresponden a elementos estructurales (de la organización del mercado habitacional) y culturales de la sociedad de acogida, que dificultan la inserción del inmigrante en todo momento de su trayectoria en el nuevo país.
\end{abstract}

Palabras Clave: Migración, trayectorias residenciales, mercado habitacional, acceso a vivienda.

\begin{abstract}
This study aims to comprehend the residential history of homes of Peruvian immigrants in the Metropolitan Region, from their arrival until their current situation, and from their own words and experiences. From an ethnographic and biographical perspective, through the residential trajectories of eight homes, it is possible to conclude that the residential trajectory of homes of Peruvian immigrants in the city of Santiago, from their arrival until now, is formed by decisional elements of change and continuity. The elements of change are the ones related to the transformation in the access to goods and/or services, and definitely, the insertion in the new city. On the other hand, the elements of continuity correspond to structural (the organization of the housing market) and cultural elements of the host society, which make difficult the insertion of the immigrant all the time of their trajectory in the new country.
\end{abstract}

Key words: Migration, residential trajectories, housing market, access to housing.

1. Doctor en Arquitectura y Estudios Urbanos, Pontificia Universidad Católica de Chile. Magíster en Sociología, Pontificia Universidad Católica de Chile. Socióloga, Pontificia Universidad Católica de Chile. Profesora Asistente Escuela de Trabajo Social PUC.

Correo electrónico: arasse@uc.cl

2. Trabajadora Social, Magíster en Trabajo Social Pontificia Universidad Católica de Chile. Correo electrónico:

angelicasanzanamedina@gmail.com 


\section{Introducción}

En los últimos años se ha producido un incremento significativo de la población inmigrante en el país, alcanzando, de acuerdo al CENSO 2017, alrededor del 4\% de la población total que habita en territorio nacional.

Junto a este marcado crecimiento, se evidencia también un cambio en el perfil migratorio respecto a la primera mitad del siglo XX, caracterizándose en la actualidad principalmente por una preponderante inmigración latinoamericana (INE, 2012; DEM, 2010). La localización de esta nueva población de inmigrantes se concentra mayoritariamente en la Región Metropolitana (DEM, 2010; Martínez, 2003). Siendo las comunas con mayor concentración de población extranjera, en primer lugar, la comuna de Santiago, y le siguen las comunas de Recoleta, Quinta Normal, Independencia y Estación Central (Arias, Moreno \& Nuñez, 2010).

$\mathrm{Al}$ respecto, diversos estudios realizados en Chile durante los últimos quince años revelan que los inmigrantes latinoamericanos, especialmente los peruanos de menores ingresos, se concentran en el centro de la ciudad al momento de su llegada o arribo al país (Margarit \& Bijit, 2014; Stefoni, 2004, 2013; Garcés, 2007, 2011, 2012; Arias, Moreno \& Nuñez, 2010; Ducci \& Rojas, 2010; Torres \& Hidalgo, 2009), desplazándose posteriormente hacia las comunas más alejadas del centro (Garcés, 2011b ; Arias, Moreno \& Nuñez, 2010; Stefoni, 2004).

La concentración de extranjeros latinoamericanos de menores ingresos en determinados sectores del centro de la ciudad de Santiago suele manifestarse por la oferta de empleo, el equipamiento urbano y conectividad, tal como la existencia de redes de solidaridad e intercambio de información entre inmigrantes (Margarit \& Bijit, 2014; Garcés, 2012; Torres \& Hidalgo, 2009). Pero también por las características que presenta el centro de la ciudad como mosaico socioespacial, donde convergen habitantes de ingresos medios, de ingresos altos (en menor medida), así como móviles de bajos ingresos (Contreras, 2011). Entre estos últimos, inmigrantes latinoamericanos de bajos ingresos, que encuentran en las viviendas deterioradas opciones de arriendo informal de piezas compartidas en una localización central (Margarit \& Bijit, 2014; Stefoni, 2013; Contreras, 2011; Schiappacasse, 2010; Torres \& Hidalgo, 2009).

Los altos precios de arriendo, los antecedentes financieros requeridos, y la existencia de prejuicios entre los agentes que representan la oferta conducen al arriendo irregular de viviendas en precarias condiciones (Margarit \& Bijit, 2014). Diversos estudios muestran que muchos inmigrantes en Chile residen en precarias condiciones habitacionales, hacinados y con carencia de servicios básicos (Margarit \& Bijit, 2014; Garcés, 2011b; Ducci \& Rojas, 2010; Torres \& Hidalgo, 2009). Estas condiciones habitacionales, propias de la primera instalación en la ciudad, se caracterizan principalmente por desarrollarse al interior de viviendas con habitaciones subdivididas o departamentos, ambos de uso colectivo, compartiendo baño y cocina, entre otros (Margarit \& Bijit, 2014; Ducci \& Rojas, 2010; Torres \& Hidalgo, 2009). En el caso de las viviendas con habitaciones subdivididas, se ha observado que una habitación es ocupada por más de una familia, en ocasiones residiendo hasta seis núcleos familiares en un mismo espacio (Margarit \& Bijit, 2014).

En términos de vivienda en propiedad, el acceso a vivienda social para la población inmigrante de bajos ingresos ha sido históricamente limitado. Actualmente no existe una política habitacional del Ministerio de Vivienda y Urbanismo que aborde la situación habitacional de los inmigrantes de manera particular, una vez adquirida la residencia definitiva deben postular a vivienda cumpliendo los mismos requisitos que un chileno en "igual condición económica". Sin considerar que su condición de inmigrantes, principalmente en la etapa de llegada, les excluye del mercado habitacional formal (Fundación Instituto de la Mujer, 2018).

Si bien existen muchos estudios nacionales que dan cuenta de la inserción inicial de los inmigrantes en la ciudad (Margarit \& Bijit, 2014; Stefoni, 2004, 2013; Garcés, 2007, 2011b, 2012; Arias, Moreno \& Nuñez, 2010; Ducci \& Rojas, 2010), no existen descripciones claras de su trayectoria residencial desde este momento de arribo hacia su establecimiento más permanente en la ciudad, el cambio de condiciones habitacionales que vendría aparejado a esto, y en especial, la forma en que pese a sus desventajas consiguen producir este cambio hacia condiciones más favorables. 
En este marco, este trabajo busca comprender la forma en que se producen las trayectorias residenciales de los hogares de los inmigrantes peruanos de bajos ingresos en la Región Metropolitana, desde su llegada hasta el asentamiento habitacional, a partir de sus particulares experiencias y percepciones. A través del análisis de la trayectoria, se puede ver, por una parte, cómo el inmigrante se va integrando y va consolidando su situación, pero, por otra parte, cómo va teniendo dificultades para consolidar su situación habitacional, producto de las reglas del juego del mercado habitacional y las formas culturales predominantes de relación con los inmigrantes.

Se ha hecho foco en los inmigrantes peruanos dado que esta inmigración es uno de los movimientos migratorios más importantes de las últimas décadas en Chile. Si bien hay otros grupos con migración más intensa en los últimos años, la migración peruana, al tener una historia más larga, nos permite analizar trayectorias residenciales en todas sus etapas.

En el actual escenario de aumento de la migración, resulta primordial comprender cómo se está dando la incorporación de los migrantes en especial en lo concerniente a vivienda, puesto que en este ámbito no existen medidas desde la política pública que permitan a los inmigrantes de bajos ingresos acceder a una vivienda de manera formal en los primeros años desde su llegada. De esta forma, se espera contribuir a la reflexión crítica sobre la importancia que tiene que el país desarrolle una postura responsable frente al fenómeno de la migración, no solo en términos de condiciones de entrada, sino pensando en la incorporación a largo plazo de los migrantes en nuestra sociedad.

\section{Problemática y estado del arte}

\section{Inclusión social de los inmigrantes en las sociedades de llegada}

El fenómeno de la migración no es algo nuevo, por el contrario, ha sido una característica permanente de las ciudades desde el comienzo de la historia (Margarit \& Bijit, 2014). En efecto, a nivel internacional se ha desarrollado una serie de teorías explicativas de la migración internacional, que desde diferentes perspectivas analizan la migración como una consecuencia de un conjunto de causas diversas, tanto en los países de origen como en los receptores (Portes, 2009; Micolta, 2005; Massey \& Durand, 2003; Martínez, 2000; Arango, 1985, 2003).

De acuerdo a lo propuesto por Portes (2009), son cuatro las escuelas más importantes que han estudiado esta temática: 1) el enfoque neoclásico, basado en un cálculo individualista de los beneficios y los costos de los posibles futuros migrantes; 2) el enfoque de la nueva economía, basado en el concepto de la privación relativa y en el especial hincapié que hace en las estrategias familiares para superar las imperfecciones del mercado capitalista en las regiones emisoras; 3) la perspectiva del sistema mundial, fundada en los conceptos de penetración estructural y desequilibrio de las áreas periféricas que crean las condiciones para los desplazamientos en masa hacia el exterior; y 4) el enfoque de las redes sociales, basado en los conceptos de dependencia de trayecto y los costes decrecientes de la migración.

El enfoque neoclásico asume que la decisión de migrar es individual y racional en base a un cálculo de costes y beneficios, motivada fundamentalmente por las diferencias de salario y de empleo entre países. De esta manera, los desplazamientos migratorios tenderían a producir un equilibrio en la distribución espacial de los factores productivos. Este enfoque supone, por extensión, la diversificación de la población migrante sobre la base de la división internacional del trabajo, así como el equilibrio general entre emigración e inmigración.

En esta misma línea, el enfoque de la nueva economía de las migraciones, comparte con la teoría neoclásica que la piedra angular básica de la decisión de migrar obedece a una decisión racional, motivada por las diferencias salariales y laborales entre países. Pero a diferencia de esta, propone que las decisiones migratorias no obedecen exclusivamente a la voluntad de actores individuales, sino que se insertan en unidades más amplias de grupos humanos -familias u hogares o, grupos familiares-, donde la migración se plantea como una estrategia familiar, 
en las que se actúa colectivamente para maximizar no solo la esperanza de obtener nuevos ingresos, sino también para minimizar los riesgos económicos. El enfoque de las redes sociales aporta a este enfoque la noción de cadenas migratorias, invisibles redes que se tejen entre familiares, amigos y paisanos y entre los orígenes y los destinos, que tienen una gran influencia en la direccionalidad y periodización de las migraciones, así como en la selección de los migrantes, y también en el asentamiento y adaptación a las nuevas condiciones de la nueva ciudad (Micolta, 2005; García, 2003; Massey, \& Durand, 2003; Martínez Veiga, 2000; Arango, 1985, 2003).

Como puede verse, estos modelos más que excluyentes, son complementarios. Es muy posible que en los procesos de migración y las trayectorias residenciales se constituyan varios de los elementos decisionales que proponen estos enfoques. Sin embargo, el fenómeno de las migraciones masivas no se puede comprender en ausencia del análisis de conceptos como mundialización y sociedad global (Silva, 2006). En este sentido, la perspectiva del sistema mundial proporciona una visión más global de la migración, concebida como consecuencia de la globalización económica y la transnacionalización de los mercados. Al alero del concepto de mundialización, la migración deja de ser solo una motivación individual de algunos sujetos y pasa a ser parte estructural del sistema global, donde los migrantes no son considerados como individuos sino como grupos o sectores, protagonistas del sistema global total (Micolta, 2005; García, 2003; Massey \& Durand, 2003; Martínez, 2000; Arango, 1985, 2003).

De esta manera, podemos comprender que la migración no es simple consecuencia de las opciones individuales de los migrantes, aun cuando estos puedan experimentar sus propias emigraciones como el resultado de sus decisiones personales. La opción misma de emigrar es producto de un proceso social, enmarcada en los procesos mundiales de desarrollo económico, y que se vincula con las políticas susceptibles de haberlos activado, entre otros.

\section{Integración de los inmigrantes en la ciudad}

La inclusión de los inmigrantes en las sociedades de llegada fue inicialmente estudiada desde los fenómenos migratorios que tienen lugar en los países desarrollados como sociedades de destino de los flujos migratorios (Garcés, 2011a; Glick \& Caglar, 2009). Los enfoques de estas investigaciones se centran en las teorías clásicas de la "asimilación", basada en la perspectiva de una economía unificada, en la que los migrantes inician su integración desde la parte inferior y gradualmente ascienden ocupacionalmente, a la vez que ganan la aceptación social (Wilson \& Portes, 1980).

En esta perspectiva, uno de los grandes modelos teóricos que ha estudiado el asentamiento residencial de los migrantes en las ciudades, es el llevado a cabo por la escuela de Chicago a comienzos del siglo XX, que considera las pautas residenciales de los inmigrantes como un fenómeno ligado a su proceso de asimilación a la sociedad de recepción (Marcos \& Mera, 2018; Wilson \& Portes, 1980). En este sentido, el desplazamiento de las poblaciones inmigrantes se emplaza desde el centro hacia fuera, en la medida que la progresiva integración de los inmigrantes en la sociedad receptora supondría una mayor dispersión residencial (Garcés, 2011b). Esto en la medida en que van generando nuevas redes y van alcanzando una estabilidad que les permite trasladarse hacia otras localizaciones menos centrales, en las que pueden acceder a viviendas en mejores condiciones habitacionales.

Otro modelo conceptual relativo al asentamiento de los inmigrantes parte de la noción de enclaves étnicos, en que la concentración geográfica de inmigrantes, asociada a una similar concentración de comercios o empresas de inmigrantes que les proveen servicios o los emplean, permiten recrear en la nueva ciudad un espacio cultural similar al de su lugar de origen (Garcés, 2011b; Wilson \& Portes, 1980). Desde esta perspectiva los "enclaves étnicos" son vistos como consecuencia de una estrategia étnica, determinada por las características del grupo y la estructura de oportunidad. Estas estrategias étnicas serán particularmente importantes no solo en la organización interna de los negocios, en la forma en que articulan familia, capital y trabajo, sino también en la forma en que organizan su emplazamiento en la ciudad (Garcés, 2011a). 
Estudios más recientes incorporan el papel que cumplen otros factores en la dinámica de asentamiento, tanto los vinculados a las prácticas de los mismos actores en movimiento, como los asociados con las condiciones estructurales que brinda la sociedad receptora a los diversos grupos inmigrantes (Marcos \& Mera, 2018). Algunos investigadores han enfatizado la importancia de las redes sociales de inmigrantes en su asentamiento en la ciudad, dando cuenta del papel que desempeñan en las estrategias de adaptación de los inmigrantes, otros reconocen el papel de las asociaciones voluntarias establecidas por los inmigrantes, mientras que hay quienes se han centrado directamente en las organizaciones de base comunitarias inmigrantes (Marcos \& Mera, 2018; Cordero, 2005).

En relación a las condiciones estructurales que brinda la sociedad receptora, Borjas (2002) muestra que los hogares inmigrantes tienen menores tasas de propiedad de vivienda que los hogares nativos, brecha que se amplía considerablemente durante los últimos veinte años. Los factores que generan esta brecha tienen que ver con los ingresos de los hogares, las restricciones crediticias, la estructura de mercado de vivienda y con los costos de las viviendas, pero principalmente, con las diferencias en las opciones de ubicación residencial realizadas por inmigrantes y nativos (atribuible a la diferencia en la estructura de mercado entre regiones o las diferencias regionales de los costos de vivienda) (Borjas, 2002).

En este sentido, los elementos que configuran el asentamiento de los inmigrantes en una ciudad son múltiples, y si bien existen modelos que describen el proceso en términos generales para cualquier ciudad, muchos de los factores involucrados tienen relación con cuestiones específicas, propias de cada ciudad y cada grupo, como la estructura y reglas del juego del mercado de vivienda en la ciudad, o las características del grupo en términos de asociatividad, entre otros.

\section{Condicionantes normativo-institucionales de acceso a vivienda de inmigrantes en Chile}

En el caso chileno todo lo que se señala en la literatura internacional debe comprenderse incorporando tres condicionantes particulares: la política migratoria, la política de vivienda y el mercado habitacional privado.

La normativa que regula la vida de los inmigrantes en el país se mantiene aún fundada en un marco legal creado en la década de los setenta (Garcés, 2011a), cuyo cuerpo legal establece regulaciones orientadas principalmente al control de extranjeros y seguridad territorial. Pese a todas las mejoras que se han realizado desde la administración pública, estas solo resuelven problemas puntuales, que en definitiva no hacen más que evidenciar la necesidad de generar una nueva política migratoria.

Para residir indefinidamente en Chile y desarrollar cualquier clase de actividades, sin otras limitaciones que las que establezcan las disposiciones legales y reglamentarias en el país, los extranjeros deben obtener la permanencia definitiva (DEM, 2018; Gobierno de Chile, 1975).

Sin embargo, solo pueden optar a la residencia definitiva una vez cumplido un periodo de al menos dos años con residencia temporal, la que en nuestro país está sujeta a contrato laboral. Por lo tanto, para obtener la residencia definitiva deben acreditar el permiso de residencia temporal y un contrato de trabajo continuo y de un solo empleador, todo comprendido en un periodo no inferior a dos años. De manera que si el inmigrante cambia de trabajo deberá reiniciar el proceso de cero (Riveros, 2013; Thayer, 2013; Stefoni, 2013).

La política habitacional que promueve el acceso a la vivienda en los grupos de menores ingresos en Chile se basa en el sistema de subsidio a la demanda. Básicamente, consiste en que a través de la asignación de este "voucher" las personas deben adquirir una vivienda en el mercado privado (Rivera, 2012; Casgrain, 2010; Sabatini, 2000).

Como este modelo privilegia la propiedad privada de la vivienda, solamente pueden acceder a vivienda las personas que acrediten un mínimo de ahorro, y en la mayoría de los programas, capacidad de endeudamiento a través de un crédito hipotecario en el mercado financiero. En el caso de los inmigrantes, deben además certificar la residencia definitiva. Estos requisitos dejan habitualmente fuera a los inmigrantes, salvo a una pequeña proporción: quienes cumplen con la residencia definitiva y con la solvencia económica para garantizar el ahorro y el crédito hipotecario. 
Como una alternativa de solución distinta a la prevaleciente, recientemente a partir del año 2014 el Ministerio de Vivienda y Urbanismo implementa el "programa de subsidio de arriendo de vivienda". Este programa está destinado a las personas que necesitan apoyo económico para arrendar un lugar donde vivir (Matamala, 2015; MINVU, 2013). Permitiendo el acceso al arriendo de vivienda a personas que no cuentan con capacidad de ahorro y que no son sujetos de créditos. Sin embargo, desde su implementación hasta la actualidad ha presentado ciertos inconvenientes que han propiciado una escasa concreción de los subsidios programados anualmente (Matamala, 2015), ello a razón de que las personas propietarias de viviendas privadas son reticentes a que las familias de bajos ingresos arrienden sus viviendas, a pesar del subsidio estatal, por un tema de estigmatización para con las personas de bajos ingresos y, en particular, con los inmigrantes.

En este marco, una persona migrante sin residencia definitiva no tiene posibilidad de postular a un subsidio habitacional y debe acceder una vivienda de manera individual, a través del mercado habitacional privado. Acceder a un crédito hipotecario para la compra de una vivienda, así como acceder a un arriendo formal, requiere demostrar garantías satisfactorias, como contrato indefinido, antigüedad laboral y estabilidad en los ingresos, lo que resulta imposible para familias llegadas recientemente. Estas dificultades promueven la exclusión de los migrantes del mercado formal de vivienda, al menos en sus primeros años de residencia en el país.

\section{Metodología}

Para dar cuenta de las trayectorias residenciales de los hogares inmigrantes peruanos de bajos ingresos, se diseñó un estudio biográfico, que reconstruyó la historia residencial de 8 hogares que llevaban entre 10 y 15 años en el país, a partir de entrevistas semi estructuradas.

Se decidió trabajar con hogares y no con personas, en la medida en que cuando es un hogar el que se traslada hacia el nuevo país, es más evidente la intención de asentamiento. Que lleven entre 10 y 15 años en el país permite dar cuenta de una trayectoria larga, pero al mismo tiempo, posible de ser recordada.

La muestra de 8 cosas buscó recoger una diversidad de situaciones, y con ello, asegurar que distintas condicionantes y distintas formas de ver y de vivir la ciudad quedaran incluidas en la muestra. Así, se esperaba que las biografías, aún desde su diversidad, expresaran los elementos comunes en la experiencia de asentamiento de los inmigrantes. Se incluyó hogares que aún residían en el centro y/o en comunas pericentrales, y otros en sectores periféricos de la ciudad, resguardando la inclusión de personas con y sin vivienda propia. Adicionalmente, se incorporaron hogares con y sin hijos.

Las entrevistas fueron planteadas de manera individual con el jefe de hogar o su cónyuge, o bien, en pareja, dado que lo que se buscaba reconstruir es la trayectoria del hogar. En conjunto con los entrevistados, se construía una línea de tiempo con la historia de los barrios y viviendas en que ha residido, desde la última vivienda en que residió en Perú, hasta su vivienda actual en Chile. Con base en este material, se profundizaba respecto a cada barrio y vivienda de acuerdo a una pauta flexible, con foco en cuatro temas: relaciones sociales y redes, mercado habitacional y condiciones habitacionales y de habitabilidad. El análisis se realizó generando códigos abiertos dentro de cada uno de estos grandes temas, e incorporando aquellas temáticas emergentes no consideradas inicialmente. 


\section{Resultados}

\section{Proyecto Migratorio (antes de llegar a Chile)}

Entre las motivaciones para migrar se evidencia una alta relación del proyecto migratorio con la deficiente situación socioeconómica familiar. Aunque no todos lo declaran abiertamente, la carencia económica se manifiesta en sus relatos. Así la decisión de migrar a Chile se basa fundamentalmente en la información relativa a las oportunidades laborales y la posibilidad que estas oportunidades podrían brindarles para ahorrar y/o enviar remesas a sus familias que quedaban en Perú. En este sentido cabe señalar el rol decisivo que jugaron los familiares que orientaron sus proyectos migratorios, puesto que estos familiares fueron quienes impulsaron y determinaron la decisión de migrar en los entrevistados, principalmente en base a la información relativa a las oportunidades laborales que había en Chile y, también, al apoyo que ellos les brindarían para comenzar su estadía. Pese a que no todos vinieron con la idea de quedarse definitivamente en Chile, dado que esta decisión implicaba comenzar de cero en un país nuevo, la totalidad de los entrevistados se motivaba con la idea de migrar a trabajar y ahorrar dinero por un buen par de años, y luego si no lograban sentirse integrados retornarían a sus países.

Fue una decisión muy, pero muy dificil para nosotros. A ver, como digo, yo ya tenía a mis hijas estudiando, pero para mí fue difícil dejarlas. Yo era...solamente yo era, participaba en mi casa, yo, todo, todos los quehaceres en la casa entre cocinar, lavar, planchar y todo. Entonces, dejar a los hijos, yo era como un poco mamá gallina, que no me gustaba este, no es que tanto acaparadora (...) Entonces cuando vi que la situación ya no, no, no daba para más, la situación económica, y cinco hijos. Entonces dije no, voy, me voy, porque además ya tenía a mi tía que estaba aquí, ya había venido un año antes y mi tía me dijo que sí, que se podía conseguir trabajo. Y dije a mi tía, vamos y, así, así nació la idea de venirse, pero fue dificil, muy, muy, muy dificil (Entrevistada, hogar 8).(Bustos, A y Vidal, C. 2014).

El conocimiento que tenían de Santiago y de Chile era escaso, pero percibido como suficiente para tomar la decisión de emigrar. El antecedente de mayor incidencia es el relacionado con la situación económica laboral que les podía proporcionar el país. La segunda referencia que aparece con frecuencia en los relatos es la representación de Santiago como una ciudad ordenada.

Yo tenía otros conocidos más, hablábamos por messenger y bueno, yo dije: ¿por qué no voy para allá?, así que voy a probar suerte, o sea, que había trabajo, que te alcanzaba la plata si tú querías mandar para allá, a tu mamá, a tu papá, eso me contaban (Entrevistado, hogar 7).

Así, la percepción relativa a la situación económica laboral que les podía proporcionar Chile, influenciada por la situación económica laboral que presentaban los hogares en su país de origen, es uno de los factores preponderante a la hora de tomar la decisión de migrar. Esto al punto de dejar de lado aquellas convicciones o apreciaciones poco favorables de Chile, en pos de la necesidad de generar ingresos.

Consecuentemente, las proyecciones que se plantearon los entrevistados antes de llegar tienen estrecha relación con las motivaciones y las expectativas que se forjaron a partir de la información recibida de sus familiares inmigrantes en Chile. Primordialmente planearon llegar directo a trabajar -por más sacrificados que fueran el oficio y la forma de habitar- y en base a eso ahorrar dinero -lo que más pudieran- para ayudar a sus familias.

Yo decía, si yo me quedo a trabajar allá, decía voy a juntar plata y traer a mi familia, a mis hermanos, mi entorno, eso es lo que yo pensaba, ayudar para que estudien, que tengan carreras o algo. Si es que nos quedábamos (Entrevistada, hogar 1).

La información y orientación que reciben los migrantes en la etapa de proyecto migratorio proviene esencialmente, de las relaciones personales y de amistad. En la mayoría de los casos se trata de familiares o parientes directos de los migrantes que llevan tiempo residiendo en Chile, tías, tíos, primos, cuñados y, en algunos casos, de los propios padres de los migrantes que han llegado antes que su familia. La información que transmiten se relaciona con las alternativas de trabajo y las formas de habitar en los primeros años de residencia. Y aunque esta información reviste sacrificio, esta no desalienta a los migrantes, por el contrario, fijan sus objetivos en ese escenario. 
Nosotros sabíamos que aquí, por lo que dijeron mis cuñadas, se trabaja de nana en casas. Así sea una profesora, ingeniera, uno viene de nana, porque no tiene documentos legales, para trabajar de su profesión. Pero también teníamos claro, que no íbamos a ser como otras personas que han salido del país que ganan su dinero y van a Perú para que lo desperdicien, no. Nosotros llegamos con metas claras, primero casa, lo primero donde vivir. Sabiamos, porque nos habian contado, que íbamos a venir a vivir en piecitas, en cuartos. A compartir baño, a compartir cuartos, lo sabiamos, lo teníamos claro (Entrevistada, hogar 6).

La relevancia que implica el hecho de tener dónde residir al momento de la llegada al nuevo país e inicio del recorrido residencial, se expresa como una condición transcendental al momento de tomar la decisión de realizar la migración. Todos los hogares entrevistados valoran tener un lugar donde llegar como otro factor determinante para concretar el traslado.

En ese tiempo ¿recién llegado? No, era difícil, no tenía otra opción. Y principalmente por eso yo vine, porque tenía dónde llegar, ¿me entiende? (Entrevistado, hogar 7).

\section{Llegada a Chile (inicio de la trayectoria residencial)}

En relación a las opciones de vivienda que tenían al momento de la llegada, casi la totalidad de los entrevistados llegaron a vivir en el centro y pericentro de la ciudad. En primera instancia, de allegados en las viviendas de los familiares o parientes directos que justamente incidieron en la decisión de migrar.

La condición de allegados implicaba el compartir los espacios de la vivienda, representado en hacinamiento en algunos casos, y la contribución económica para solventar los gastos básicos: electricidad, agua, gas y alimentación, fundamentalmente. Esta condición de allegados perdura en estos hogares un tiempo de alrededor de tres años.

Con posterioridad, sus mismos familiares los contactan directamente con arrendatarios de piezas "informales", en la medida en que comienzan a buscar mayor autonomía e independencia como núcleo familiar, en un espacio físico "propio". También son sus familiares quienes les brindan los primeros contactos y datos laborales. Generalmente se trata de datos directos, un vecino que tiene algún tipo de negocio o a través de sus mismos empleadores, quienes buscan trabajadores extranjeros de preferencia. En este sentido, resulta interesante observar como la dimensión residencial se va configurando como escenario de la construcción de las redes sociales, proveedoras de flujos de informaciones claves para lo residencial y otras dimensiones de vida, como la laboral a través de las alternativas de trabajo.

No, es que yo ya los encontré a ellos viviendo ahí, a mi hermana y mi cuñado. Yo cuando llegué ellos ya vivian, ya estaban alquilando esa casa ... y mi hermana me decía: ya; un vecino de ahi tiene un trabajo; tenía un radio taxi, yo llegué ahí y me fui a lavar autos, en un radio taxi, cosa que me sirvió... (Entrevistado, hogar 7).

Así, el factor familiar juega un rol importante en la decisión de migrar y en el primer momento de asentamiento, más que otros canales de información. Los relatos sugieren que la migración se comprende a escala familiar, pues son los familiares quienes promueven la migración y proveen un primer asentamiento, y luego estos mismos familiares son quienes les orientan durante los primeros años de residencia en Chile.

\section{Fase intermedia}

Es en este momento cuando se busca acceder a vivienda de manera directa y personal, pero sus opciones de residencia se ven reducidas por las exigencias propias del mercado de vivienda en el país. Aun cuando todas las orientaciones de sus familiares los llevaban hacia la búsqueda de alojamiento en el mercado habitacional informal, todos los inmigrantes entrevistados intentaron en paralelo acceder al arriendo de viviendas en el mercado habitacional formal, a través de datos proporcionados por vecinos, compañeros de trabajo o avisos en el barrio. Sin embargo, todos los intentos fueron fallidos, dado que no cumplían con los requisitos que les exigían los propietarios de estos inmuebles (habitualmente formalidad laboral y/o nivel de ingreso familiar). La exclusión del mercado formal los lleva hacia el mercado habitacional informal, que le habían recomendado originalmente sus redes familiares. 
Es que no había, cuando nosotros fuimos a ver no habia, porque pedían como contrato indefinido, y mi esposo era como temporario... (Entrevistada, hogar 2).

Fueron las condiciones que ahora piden para arrendar, porque piden aval, porque te piden que ganes sobre 800 mil pesos (Entrevistada, hogar 5).

Adicionalmente, los hogares de inmigrantes peruanos relatan haber sido discriminados y estigmatizados por su condición de inmigrantes y su nacionalidad. No en pocos casos fueron impedidos de consultar por un arriendo. Tan solo al oír su acento, recibían una negativa frontal, recibiendo como respuesta un "no arrendamos a peruanos". La explicación que les daban, cuando lo hacían, se refería a que los peruanos son muy fiesteros, bulliciosos y desordenados, o por temor al subarriendo del inmueble.

\begin{abstract}
Llamábamos a otros para departamento, nos escuchaba y decía ¿son peruanos? Sí. ¡Ah! no, no arriendo a peruanos. $Y$ entonces haber, y varios, fueron varios los departamentos a los que llamamos, pero no, y siempre, ¿son peruanos? Sí, ¿cuántos son? Tantas personas. No, muchas personas y, si son peruanos, menos. No, siempre nos, por peruanos siempre nos, nos negaban. Pero ¿por qué no? No, porque son muy bulliciosos, hacen fiestas...Pero nosotros personas tranquilas (Entrevistada, hogar 8).
\end{abstract}

En este marco, los entrevistados señalan que adoptan las recomendaciones de sus más cercanos, y ante la inestabilidad laboral y sin residencia definitiva, se vuelven hacia el arriendo informal de piezas en viviendas subarrendadas. Lo que propicia este tipo de arriendo es precisamente la informalidad en que se desarrollan, ya que ni las propiedades ni los arrendatarios cumplen con los requisitos del mercado formal. Se les exige garantizar el mes de arriendo y pagar por anticipado un mes de garantía, pero no necesitan acreditar ninguna otra condición, y acceden a una vivienda a un precio asequible a su condición económica familiar. Adicionalmente, al estar este mercado principalmente constituido por migrantes, se reduce el elemento de discriminación.

En la mayoría de los casos, los primeros arriendos a los que se accede corresponden a piezas "habilitadas" en casa antiguas o, en galpones subdivididos, en estado de deterioro y abandono. En otros casos, se trata de piezas compartidas, pero en departamentos. No obstante, en todos los casos, como lo que arriendan son piezas, el uso del resto de los espacios de la vivienda es compartido.

Esas casonas antiguas, que se están cayendo. Antes era un hotel, según lo que nos explicó la dueña. Pero estaba en malas condiciones, y ahí sacaron todo y lo arrendaban por pieza, a extranjeros. Algunas eran amplias, pero no eran muy buenas, con pasajes oscuros, poca luz. Los baños eran compartidos, afuera. Me daba miedo porque hay que salir a los callejones para llegar al baño, y como era un Hotel, toda esa construcción era vieja. Eran muchas habitaciones, de 14 a más. En cada habitación era harta gente, familias con niños, con todo... (Entrevistada, hogar 1).

Las condiciones de habitabilidad de estas viviendas son deficientes y se encuentran principalmente determinadas por el deterioro que presentan estas edificaciones, que afecta a las instalaciones domiciliarias de agua, alcantarillado, electricidad y gas, que muchas veces están hechas de forma rudimentaria, con los riesgos que esto conlleva. De esta forma, estas viviendas de uso colectivo no proporcionan protección, saneamiento, ni confort, y, por el contrario, propician hacinamiento e insalubridad.

En este contexto, entre los aspectos de habitabilidad que más señalan les incomodaba y/o desagradaba de estos lugares, es el tener que compartir áreas de uso cotidiano y vital como el baño, la cocina y lavadero. Así como las características medioambientales que les proporcionaban estos lugares, tales como: la escasa iluminación y ventilación, el frío y la humedad, plaga de insectos, entre otros.

No tenía ventilación, no tenía ventanas, era oscura, era oscura, eso me aburría, al cocinar y todo (Entrevistada, hogar 4).

Fría, y que compartía baño, a pesar de que fue un poquito mejor que las anteriores, pero igual tenía que compartir baño. Colgar la ropa, se nos perdieron varias prendas, porque todos colgaban en el mismo espacio común (Entrevistada, hogar 6).

Que aparecian muchos chinches. Cuando mis hijas un día me dice mamá tengo tantas picaduras, oh le digo ¿habrá pulgas? No, me dice. Me enseña sus brazos, todos llenos de picaduras. Ay mamá me dice, y apesta tanto. Compramos remedio, todo, le echamos. Nos vamos a buscar otra casa (Entrevistada, hogar 8). 
Así, si bien las motivaciones tras cada de cambio de vivienda son particulares y variadas, es posible identificar cuatro motivaciones transversales a los relatos de los entrevistados: encontrar algo mejor, más cómodo, con algo más de privacidad y con algo más de espacio. Estas necesidades encuentran explicación en las deficientes condiciones que les proporcionaban estas piezas compartidas, y en las nuevas necesidades que debían afrontar una vez que iban consolidando la reunificación familiar.

\begin{abstract}
Ahi la motivación era que íbamos a traer a los niños y la otra que esa era muy chiquitita, a parte que el dueño no aceptaba niños, sí, eso. Entonces lo que nos motivó a cambiarnos fue eso, que venían los niños para acá... (Entrevistada, hogar 3).
\end{abstract}

Porque había 15 personas para un solo baño, ese era el mayor motivo. Me tenía loca (Entrevistada, hogar 6).

Pese a que sus motivaciones les impulsaban a buscar una vivienda en mejores condiciones habitacionales y de habitabilidad, estos hogares todavía no alcanzan una consolidación que les permita acceder a otro tipo de vivienda más que a otras piezas, siempre en el centro y pericentro de la ciudad. A través de vecinos, compañeros de trabajo, y recorriendo, encuentran piezas en mejores condiciones, y se van mudando, siempre dentro de un contexto de informalidad y precarias condiciones de habitabilidad.

\begin{abstract}
Mi cuñada, siempre, como ella conocía nos avisaba cuando se desocupaba un sitio. Buscando algo que pudiese ser un poco mejor que la anterior. Elegimos esa, porque el dinero nos alcanzaba y, porque como le digo entre esa y la anterior, era un poquito mejor, por la privacidad. Porque el dinero nos alcanzaba para un poquito más (Entrevistada, hogar 6).
\end{abstract}

Aunque esta etapa se perciba como una condición pasajera, en los relatos de los entrevistados perdura por varios años. En efecto, pese que los hogares declaran haber tenido conocimiento previo a la emigración de llegar a habitar en estas condiciones, esta no es una condición que les conforte. Por el contrario, uno de sus objetivos es alcanzar un asentamiento residencial en mejores condiciones habitacionales, sin embargo, esto se entiende como secundario en relación a mantener su trabajo, ahorrar y ayudar a sus familias.

\title{
Asentamiento
}

El acceso residencial que sigue a esta etapa se da a través del mercado formal. Ya con la posibilidad de acreditar contrato de trabajo, liquidaciones, renta y aval; el acceso a vivienda transita de piezas a viviendas personales. En algunos casos, casas o departamentos totalmente independientes, y en otros casos, departamentos interiores, edificados en la parte trasera o lateral de una vivienda, con acceso independiente. Algunos entrevistados incluso consiguen volverse propietarios de una vivienda.

\section{Me gustó por lo que era independiente en todo, ya, era lo mejor que había encontrado, a comparación de las demás piezas, anteriores que había vivido. Si, porque entre piezas y un departamento lo que yo buscaba para mis hijas era comodidad más que todo (Entrevistada, hogar 4).}

La posibilidad de acceder a una vivienda independiente se logra con la consolidación laboral de un integrante adulto de la familia, o bien, de la complementación de rentas entre los adultos del grupo familiar. Es, en todo caso, una estrategia y un logro familiar, no individual. Esto, sin embargo, tomó alrededor de 8 años en el caso de los entrevistados de este estudio, tiempo durante el cual vivieron en las condiciones de habitabilidad antes descritas.

\begin{abstract}
Entonces mi esposo como en Perú había sido almacenero en la fábrica de azúcar en Cartabio, acá se llama bodeguero, postuló al laboratorio NN. En el transcurso de todos estos años, yo como nana puertas adentro, siempre he ganado más que él, y yo le he pagado a él una carrera. Ahora mi esposo es ingeniero logístico. Ahora mi esposo tiene un buen puesto y un buen sueldo en el mismo laboratorio (Entrevistada, hogar 6).
\end{abstract}

Costaba más caro. Nos dijeron que había subido e igual lo pagábamos. Pero como ya nos ayudábamos en pagar, nos quedaba en un poco menos (Entrevistada, hogar 1).

En esta etapa, el rol que desempeñaron los medios de comunicación fue central. Es a través del periódico, de la televisión y de internet, que tres hogares de inmigrantes llegaron a ofertas de viviendas en propiedad publicitadas por desarrolladores inmobiliarios en estos medios; accediendo al subsidio habitacional dirigido a sectores medios. En este caso son las mismas inmobiliarias quienes prácticamente les gestionan el subsidio habitacional. 
Mi esposo siempre buscaba en internet, porque siempre los domingos da ese programa de vivienda en la tele, indican ahi que puedes comprar la casa con el decreto tal, en el canal 13 creo, hay varios. Vimos la casa, fuimos a Maipú a conocer, ver el piloto. Un caballero nos dijo que podíamos postular. Mi esposo para tener ese subsidio tenía que ir a la inmobiliaria, no es que uno postule. Él tenía que ir a la inmobiliaria y ellos tenían ganado ese decreto, y mi marido encajaba en el perfil (Entrevistada, hogar 6).

La tele, periódicos, comenzamos por internet a buscar, y como teníamos trabajo, teníamos definitiva y nos arrendaban al tiro (Entrevistada, hogar 6).

Con el tiempo, una vez que han adquirido una mayor autonomía familiar, en términos de formalidad (obtención de residencia definitiva) y laborales (estabilidad en un trabajo formal), acceden al mercado formal para la obtención de una vivienda en mejores condiciones que las que han habitado hasta entonces. Es preciso reforzar la noción de "familiar" al hablar de autonomía, porque todo lo que logran, lo logran entre todos los miembros adultos que incorporan los hogares de inmigrantes; así, por ejemplo: todos trabajan, todos aportan con los gastos y complementan rentas para acceder a viviendas. Todo en una relación de reciprocidad, aparentemente inquebrantable.

Por otro lado, lo esencial en estos relatos es que revelan que en la medida que se logran asentar y asimilar a hogares chilenos con similares características vulnerables, logran acceder a viviendas en el mercado formal. En otras palabras, el acceso a vivienda y los apoyos que logran recibir del Estado se encuentran determinados para estos hogares por su condición de vulnerabilidad económica y no por su condición de migrantes.

Estas viviendas, que reúnen buenas condiciones de habitabilidad y que han sido conseguidas a través del mercado formal de viviendas, se localizan en zonas y sectores que responden a la situación económica de los hogares de inmigrantes peruanos, pero que generalmente no coinciden con sus primeras preferencias residenciales. Principalmente, en comunas periféricas que no tienen los niveles de equipamiento y servicios característicos del centro.

Yo veía Puente Alto muy lejos, muy lejos. ;Me costó, digo yo en lo personal, y a mis hijos también les costó mucho acostumbrase acá...ay! esta vivienda para mí es un palacio. Es grande, para mí es espaciosa. Tiene su sala, un espacio que hay un de baño, tiene un comedor, cocina, un patio y una entrada que es estacionamiento. Y jardin. Dormitorios, son tres dormitorios. Vivimos, cinco, seis con mi nieto. Mi hija la propietaria; mi hija y su hijo; mi hijo; y mi marido y yo. (Entrevistada, hogar 6).

Si bien una parte de los entrevistados opta por acceder a una vivienda más amplia y en propiedad en una comuna periférica, otros optan por asentarse en el centro y pericentro de la ciudad, en viviendas en arriendo, privilegiando la centralidad.

El arriendo en el centro de Santiago está súper caro, y no nos íbamos a arriesgar tampoco irnos a vivir, por poca plata y no sé a vivir en un lugar que no nos sentíamos seguros. Estoy diciendo como alrededor de Santiago, las otras comunas (Entrevistada, hogar 5).

En la actualidad, la mayoría de los hogares señala haber alcanzado cierta estabilidad laboral -con ello han regularizado su situación de migrantes, obteniendo la residencia definitiva-, están viviendo en mejores condiciones habitacionales y señalan sentir seguridad y agrado de vivir en Chile, pese a lo difícil del proceso de asentamiento.

\section{Conclusiones}

La trayectoria residencial de los hogares de inmigrantes peruanos de bajos ingresos se manifiesta como un proceso largo y complejo, que se encuentra determinado por las características sociales, culturales y económicas de estos inmigrantes, así como por las condiciones estructurales, culturales y sociales propias del país receptor.

Por una parte, las redes familiares de los migrantes peruanos configuran tanto la decisión de migrar como las condiciones de asentamiento el momento de llegar al país. Son fundamentales en la búsqueda de trabajo y en la búsqueda de vivienda independiente, y en ese sentido, están detrás de la forma que toma el proceso de incorporación 
al país de los nuevos inmigrantes. Por otra parte, la estructura privatizada de nuestro mercado habitacional, junto al alto nivel de formalización del arrendamiento, excluyen a los inmigrantes del mercado formal de vivienda. Si bien pueden contar con el dinero, el no tener antigüedad laboral o no contar con un contrato de trabajo, los excluyen del arriendo formal. A esto se suma la discriminación de la que son objeto por los propietarios que arriendan sus viviendas. A diferencia de lo que ocurre en salud o educación, en donde existe oferta pública disponible para atender estos casos, en vivienda el Estado no posee unidades que permitan hacerse cargo de estos hogares desde el sector público. Así, los migrantes no cuentan con más alternativa que el mercado informal de arrendamiento de piezas en viviendas subdivididas, en una situación de precariedad habitacional que puede durar casi una década.

En términos de localización en la ciudad, la inclusión de los hogares inmigrantes peruanos en Chile, coincide con lo planteado en la literatura internacional sobre el tema, los factores que originan que estos hogares peruanos emigren de su país hacia Chile están en directa relación con mejorar sus condiciones de vida y, en consecuencia, en la búsqueda de más y mejores oportunidades de empleos. Lo que determina que la migración de estos hogares hacia el territorio nacional tenga un origen principalmente de tipo laboral y a nivel de proyecto familiar, originada y direccionada por cadenas migratorias. Estas familias se organizan para alcanzar el máximo de beneficios económicos y sociales del grupo familiar en su conjunto. Lo económico reviste un papel primordial en el proceso de incorporación de estos hogares de inmigrantes peruanos, puesto que solo en la medida que van mejorando sus ingresos familiares, estos hogares alcanzan una estabilidad económica y financiera que les permite acceder a otras cosas, entre estas el asentamiento residencial.

En lo que se refiere a la incorporación de los hogares de inmigrantes peruanos a la ciudad de Santiago, se ha podido comprender que las trayectorias residenciales de estos hogares siguen dos patrones. El primero opera de manera similar a lo planteado en la literatura internacional: como un flujo residencial que va desde infraviviendas ubicadas en el centro de la ciudad, hacia el asentamiento en sectores periféricos, alejados del centro de la ciudad. Este desplazamiento tiende a relacionarse con mejoramiento de la situación económica a nivel familiar (cierta estabilidad laboral) y la obtención de la formalidad (residencia definitiva), que les permite pasar del alquiler informal de una pieza con deficientes condiciones de habitabilidad, hacia la compra o arriendo de viviendas en mejores condiciones de habitabilidad (principalmente compra de viviendas en estos casos).

Un segundo patrón de movimiento residencial difiere del anterior y de descrito en la literatura, en tanto se completa al interior del centro de la ciudad: algunos hogares deciden permanecer en el centro para aprovechar las ventajas de la centralidad, moviéndose hacia una vivienda en mejores condiciones de habitabilidad en la medida que la situación económica del grupo familiar mejora. En estos casos, lo que se encuentra es que los hogares prefieren mantenerse arrendando en una buena localización, en lugar de acceder en propiedad a una vivienda en la periferia. Esto es más consistente con la literatura urbana relativa a la "vuelta a la ciudad" que con los patrones asociados habitualmente a los hogares migrantes.

Si bien en un primer momento se produce concentración de los migrantes en el centro de la ciudad, se vuelve difícil catalogar esta concentración como "enclave étnico", en la medida en que la elección de localización es bastante forzosa (al haber quedado excluidos del mercado formal, que representa la mayor parte de la oferta), y que las condiciones habitacionales son tan precarias que dificultan una vinculación positiva con el resto de la ciudad (promoviendo más bien los estigmas negativos). No obstante, lo anterior, las relaciones de vecindad si promueven la formación de redes entre los migrantes, y el flujo de información entre ellos.

Más allá de lo anterior, resulta importante resaltar que las condiciones de asentamiento inicial de los inmigrantes en el país (que resultan mantenerse por varios años), vulneran las condiciones de acceso a la vivienda definidas en los tratados internacionales sobre migración, y el derecho a una vivienda digna. Más que tratarse de situaciones que ocurren como resultados de "relaciones entre privados", estas dan cuenta de las limitaciones que impone el contar con un mercado de vivienda en su totalidad privado, de la debilidad de los controles en torno a las condiciones de habitabilidad de los inmuebles en arrendamiento en sectores de la ciudad de alta concentración de migrantes, y de la ausencia de políticas sociales integrales en torno al fenómeno de la migración. 


\section{Bibliografía}

1. Arango, J. (1985). Las leyes de las migraciones de E. G. Ravenstein, cien años después. Reis, 32, 7-26.

2. Arango, J. (2003). La explicación teórica de las migraciones: luz y sombra. Redalyc, 1, 1-30.

3. Arias, G., Moreno R. \& Núñez, G. (2010). Inmigración latinoamericana en Chile. Analizando perfiles y patrones de localización de la comunidad peruana. Tiempo Y Espacio, 25.

4. BCN, C. (2012). Vivienda e Inmigración. Derecho Comparado. BCN

5. Borjas, G. (2002). Homeownership in the immigrant population. Journal of Urban Economics, 52, 448-476.25, 2014 •ISSN 0717-1714 •, 67-83.

6. CASEN. (2015). CASEN 2013 Inmigrantes. Sintesis de Resultados. Ministerio Desarrollo Social Chile.

7. Casgrain, A. (2010). La apuesta del endeudamiento en la política habitacional chilena. Revista INVI, 25(68), 155-182. http://doi.org/10.4067/S071883582010000100006

8. Castillo, M. J., \& Forray, R. (2014). La vivienda, un problema de acceso al suelo. ARQ (Santiago), (86), 48-57. http://doi.org/10.4067/S0717-69962014000100007 9. Cid, P. H. (2008). 1906/2006 Cien años de política de vivienda en Chile. Revista de Geografia Norte Grande, 39, 97-99.

10. Contreras, $\boldsymbol{Y}$. (2011). La recuperación urbana y residencial del centro de Santiago. Nuevos habitantes. Cambios socioespaciales significativos. EURE, 37, 89-113.

11. Cordero, G. (2005). Community-Based Organizations and Migration in New York City. Journal of Ethnic and Migration Studies, 31, 889-909.

12. DEM. (2010). Informe Anual. Ministerio del Interior Chile, Dirección Extranjería y Migración. Retrieved from http://www.extranjeria.gob.cl/filesapp/Informe Estimacion Poblacion Extranjeros 2008.pdf

13. DEM. (2018). Preguntas frecuentes: permanencia definitiva. Retrieved from http://www.extranjeria.gob.cl/preguntas-frecuentes/

14. Duci, María \& Rojas, L. (2010). La pequeña Lima. Nueva cara y vitalidad para el centro de Santiago. EURE, 36, 95-121.

15. Fundación Instituto de la Mujer, O. C. \& C. G. del P. en S. de C. (2018). Guía de Apoyo 2018. Soy migrante tengo derechos. Retrieved from http://www.extranjeria. gob.cl/media/2018/01/GUIA-SOY-MIGRANTE-TENGO-DERECHOS-2018.pdf

16. Garcés, A. (2007). Entre lugares y espacios desbordados. Formaciones urbanas de la migración peruana en Santiago de Chile, 5-22.

17. Garcés, A. (2011a). Comercio inmigrante y economías étnicas: síntesis y críticas de los debates vigentes. Polis, Revista de La Universidad Bolivariana, 10, 97-121.

18. Garcés, A. (2011b). De enclave a centralidad. Espacio urbano, comercio y migración peruana. Gazeta de Antropología, 27.

19. Garcés, A. (2012). Localizaciones para una espacialidad: Territorios de la migración peruana en Santiago de Chile. Chungará, Revista de Antropología Chilena, 44, 163175.

20. García, R. (2003). Un estado de la cuestión de las teorías de las migraciones. Historia Contemporánea, 26, 329-351.

21. Glick, N. \& Caglar, A. (2009). Towards a comparative theory of locality in migration studies Migrant. Journal of Ethnic and Migration Studies, 35, $177-202$.

22. Gobierno de Chile. Decreto Ley 1094 Establece normas sobre extranjeros en Chile. Última Versión 08-04-2011., Biblioteca del Congreso Nacional de Chile - www. leychile.cl - documento generado el 02-Mar-2013 22 (1975)

23. Gonzales, G. (2015). El crédito hipotecario y el acceso a la vivienda para los hogares de menores ingresos en América Latina. Revista Cepal, 85, 115-129.

24. Granados, S. (2011). Línea de vida de un inmigrante latinoamericano: desde la decisión hasta la transformación en la ciudad de Santiago de Chile. Revista Geográfica de América Central, 2, 1-15.

25. Hickmann, M; Crowley, H. \& Mai, N. (2008). Inmigration and social cohesion in the UK. The rhythms and realities of everyday life. Londres: Joseph Rowntree Foundation.

26. Imilan, W. A. (2014). Ciencia, política y el agotamiento del modelo habitacional chileno. Revista INVI, 29(80), 9-15. Retrieved from http://www.scopus.com/ inward/record.url?eid=2-s2.0-84900319595\&partnerID=tZOtx3y1

27. INE. (2012). Sintesis de resultados. Instituto Nacional de Estadisticas Chile.

28. INE. (2017) Censo de Población y Vivienda.

29. Marcos, M. \& Mera, G. (2018). Migración, vivienda y desigualdades urbanas: condiciones socio-habitacionales de los migrantes regionales en Buenos Aires.

INVI, 33, 53-86.

30. Margarit, S. \& Bijit, A. (2014). Barrios y población inmigrantes: el caso de la comuna de Santiago. INVI, 29, 19-77.

31. Martínez, J. (2003). El encanto de los datos. Sociodemografia de la inmigracion en Chile según el censo de 2002. CEPAL. Santiago de Chile.

32. Martínez Veiga, U. (2000). Teorías sobre las migraciones, 1, 11-26.

33. Massey, Douglas \& Durand, J. (2003). Capitulo 1. Los enfoques teóricos: una síntesis. In Clandestinos Migración México-Estados Unidos en los albores del siglo XXI (pp. 11-44).

34. Matamala, $N$. (2015). Vivienda colectiva en arriendo de interés social. FAU.

35. Micolta León, A. (2005). Teorías y conceptos asociados al estudio de las migraciones internacionales. Revista Trabajo Social Universidad Nacional de Colombia, 7, 59-76.

36. MINVU. D. S. N 52 (V. y U.) de 2013 Aprueba Reglamento del Programa de Subsidio de Arriendo de Vivienda, minvu.cl 125 (2013).

37. Neymarc, K. (1998). Immigrants, integration and cities: a brief review of recent literature. In Immigrants, Integration and Cities Exploring the Links. OECD proceedings. (pp. 17-31).

38. Portes, A. (2009). Migración y cambio social: algunas reflexiones conceptuales. Princeton University (Estados Unidos), 9-37.

39. Rivera, Á. (2012). Historia de la Política Habitacional en el Área Metropolitana de Santiago. Revsita CIS, Centro de Investigaciones Sociales, Techo Para Chile, $16,27-44$.

40. Riveros Marín, E. (2013). Aspectos jurídicos de la migración chileno-peruana. Una visión desde Chile. In Generación de Diálogo Chile - Perú / Perú -Chile. Documento 4: Aspectos Migratorios (pp. 1-20).

41. Rojas, Nicolás \& Dittborn, C. (2016). La migración en Chile. Breve reporte y caracterización. OBIMID.

42. Sabatini Francisco, A. F. (2000). Entre el Estado y el Mercado: resonancias geográficas y sustentabilidad social en Santiago de Chile. EURE, 26, 95-113. Retrieved from http://dx.doi.org/10.4067/S0250-71612000007900006

43. Schiappacasse, P. (2010). Segregación residencial y nichos étnicos de migrantes en Santiago. Revista de Geografia Norte Grande, $39,21-38$.

44. Silva, C. (2006). ¿Cómo viven los inmigrantes irregulares sus procesos de integración en Chile? Revista Trabajo Social PUC, 73, 157-169.

45. Stefoni, C. (2004). Inmigración y ciudadanía: la formación de comunidades peruanas en Santiago y la emergencia de nuevos ciudadanos. Política, 43, 319-336.

46. Stefoni, C. (2013). Formación de un enclave trasnacional en la ciudad de Santiago de Chile. Migraciones Internacionales, 7, $162-187$.

47. Thayer, L. (2013). Expectativas de reconocimiento y estrategias de incorporación: la construcción de trayectorias degradadas en migrantes latinoamericanos residentes en la Región Metropolitana de Santiago. Polis, 12(35), 259-285. http://doi.org/http://dx.doi.org/10.4067/S0718-65682013000200012

48. Torres, A. \&, \& Hidalgo, R. (2009). Los peruanos en Santiago de Chile: transformaciones urbanas y percepción de los inmigrantes. Polis, Revista de La Universidad Bolivariana, 8(22), 307-326. Retrieved from http://www.scielo.cl/pdf/polis/v8n22/art18.pdf

49. Wilson, K. \& Portes, A. (1980). Inmigrants enclaves: an analysis of the labor market experiences of cubans in Miami. The American Journal of Sociology, 86, $295-319$. 